\title{
Endoxifen and fulvestrant regulate estrogen-receptor $\alpha$ and related DEADbox proteins
}

\author{
Jasmin Asberger ${ }^{1,2}$, Thalia Erbes ${ }^{1,2}$, Markus Jaeger ${ }^{1,2}$, Gerta Rücker ${ }^{3}$, Claudia Nöthling1,2, Andrea Ritter ${ }^{1,2}$, \\ Kai Berner ${ }^{1,2}$, Ingolf Juhasz-Böss ${ }^{1,2}$ and Marc Hirschfeld ${ }^{1,2,4}$ \\ ${ }^{1}$ Department of Obstetrics and Gynecology, Medical Center - University of Freiburg, Freiburg, Germany \\ ${ }^{2}$ Faculty of Medicine, University of Freiburg, Freiburg, Germany \\ ${ }^{3}$ Institute of Medical Biometry and Statistics, Medical Center - University of Freiburg, Freiburg, Germany \\ ${ }^{4}$ Institute of Veterinary Medicine, Georg-August-University Goettingen, Goettingen, Germany \\ Correspondence should be addressed to J Asberger: jasmin.asberger@uniklinik-freiburg.de
}

\begin{abstract}
Breast cancer (BC) represents the most common type of cancer in females worldwide. Endocrine therapy evolved as one of the main concepts in treatment of hormone-receptor positive BC. Current research focuses on the elucidation of tumour resistance mechanisms against endocrine therapy. In a translational in vitro approach, potential regulatory effects of clinically implemented BC anti-oestrogens on ER $\alpha$, its coactivators DDX5, DDX17 and other DEADbox proteins as well as on the proliferation markers cyclin D1 and Ki67 were investigated on both the RNA and protein level. BC in vitro models for hormone-receptor positive (MCF-7, T-47D) and hormone-receptor negative cells (BT-20) were subjected to endocrine therapy. Anti-oestrogen-dependent expression regulation of target genes on the transcriptional and translational level was quantified and statistically assessed. Endocrine therapy decreases the expression levels of Ki67, cyclin D1 and ER $\alpha$ in hormonereceptor positive cells. In the hormone-receptor negative cells, the three parameters remained stable after endocrine therapy. Endoxifen triggers a downregulation of DDX5 and DDX23 in MCF-7 cells. Fulvestrant treatment downregulates the expression levels of all investigated DEADbox proteins in MCF-7 cells. In T-47D cells, endoxifen and fulvestrant lead to a decrease of all target gene expression levels. Interestingly, endocrine therapy affects DEADbox RNA expression levels in BT-20 cells, too. However, this result could only be confirmed for DDX1, immunocytologically. The investigated DEADbox proteins appear to correlate with the oestrogen-dependent tumourigenesis in hormone-receptor positive $\mathrm{BC}$ and show expression alterations after endocrine treatment.
\end{abstract} Key Words

\section{Introduction}

With an incidence of $28.2 \%$, breast cancer represents the most common type of cancer in females in Europe (1). Oestrogen-dependent gene expression regulation is known to play an important role in the promotion and progression of hormone-receptor positive breast cancer (BC) (2). Associated signalling pathways serve as targets for various approved therapeutic agents.
Oestrogen-mediated activities are major drivers for cellular changes in breast carcinogenesis characterized by the expression of the oestrogen receptor $(\mathrm{ER})(2,3,4)$. Two subtypes of ER, oestrogen receptor alpha (ER $\alpha)$ and oestrogen receptor beta (ER $\beta)$, act as transcription factors regulating gene expression of various target genes and are physiologically expressed in breast tissue (3). ERo seems

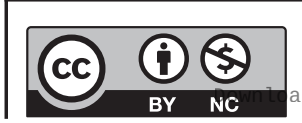


to activate proliferation, whereas ER $\beta$ rather triggers antiproliferative activity (5). Interestingly, approximately 40 to $70 \%$ of BCs exhibit a significant expression of ER $\alpha$ on tumour cell membranes. In respect of therapeutic options, these qualify for a successful approach of endocrine therapy $(5,6)$.

Endocrine therapy evolved as one of the main concepts in the adjuvant systemic treatment of hormonepositive breast cancer patients. Clinically established agents can be categorized according to different endocrine effects: selective oestrogen-receptor modulators (SERMs), aromatase inhibitors (AIs), and selective estrogen-receptor downregulator (SERD) (7).

The selective oestrogen receptor modulator (SERM) tamoxifen is the most widely used agent in BC therapy (8). Tamoxifen is a prodrug. The active metabolite, endoxifen (N-desmethyl-4-hydroxytamoxifen) is a competitive inhibitor of ER and a consecutive conformational change which results in the repression of ER transcriptional activity $(5,6,9,10)$. A previously published meta-analysis reported a significant 15-year reduction for recurrence (39\%) and mortality (30\%), for patients receiving adjuvant tamoxifen treatment for a 5-year period (11).

Fulvestrant is a selective oestrogen receptor downregulator and acts as ER- receptor antagonist only. $(12,13,14)$. This SERD is FDA-approved for the treatment of hormone receptor-positive, HER2-negative advanced $\mathrm{BC}$ in postmenopausal women with disease progression following endocrine therapy, as well as for BC patients without prior endocrine therapy (15).

Tamoxifen and fulvestrant have been used successfully for several years now and have led to a significant prolongation of progression-free survival as well as overall survival. However, new elements of the pathways have shown significant influence and therefore represent promising novel therapeutic targets. One of these is the DEADbox (DDX) protein family, which includes 38 different proteins in humans, characterized by a common conserved amino acid sequence signature (Asp-Glu-Ala-Asp, or D-EA-D) (16). The two paralogous RNA helicases p68 (DDX5) and p72 (DDX17) act as transcriptional coactivators in oestrogen-dependent transcription processes. Furthermore, functional impacts like transcriptional cofactors for the androgen receptor (17), the tumour suppressor p53 (18) and for important transcription factors (MyoD) in the differentiation of muscle cells (19) could be identified. Both factors, DDX5 and DDX17, directly bind to ER $\alpha$ and were found overexpressed in two-thirds of BC cases (20). Thus, their crucial function in breast tumourigenesis is most likely mediated by concerted enhancement of ER $\alpha$ oncogenic activities $(16,21)$. Moreover, regarding clinicopathological parameters in BC, DDX17 expression is correlated with increased relapse-free and overall survival, and inversely associated with Her2/neu expression (20). In contrast, DDX5 expression displayed no significant correlation to survival rates, but is associated with increased Her2/neu levels (20).

Several studies indicate an oncogenic role of DDX1 (22). DDX1 overexpression combined with elevated cytoplasmic DDX1 protein levels were shown to be associated with early recurrence in breast cancer (23). However, another report shows an association between the expression of DDX1 with improved local relapse-free-, distant metastasis-free- and overall survival in patients diagnosed with early stage nodenegative BC (24). In non-small-cell lung cancers (NSCLCs) DDX23 activates an oligonucleotide-based promotion (Linc00630) of metastasis and proliferation (25). To date, the role of DDX23 in BC remains undefined. DDX42 binds and counteracts ASPP2, a major apoptosis inducer known to enhance p53 transactivation of pro-apoptotic genes (26).

Current research focuses on the challenging resistance mechanisms of tumour cells towards endocrine therapy (6). This study is a translational approach targeted on the elucidation of potential effects triggered by endocrine anti-breast cancer drugs on the transcriptional and translational expression of $\mathrm{ER} \alpha$, its coactivators DDX5, DDX17 and other DEADbox proteins as well as the proliferation markers cyclin D1 and Ki67.

\section{Material and methods}

\section{Cell maintenance}

In vitro analyses were performed by employment of established BC cell lines with varying range of hormone receptor states:

T-47D, MCF-7 and BT-20 (Supplementary Table 1, see section on supplementary materials given at the end of this article) cells were routinely maintained in a humidified incubator $\left(37^{\circ} \mathrm{C}, 3.5 \% \mathrm{CO}_{2}\right)$ RPMI 1640 Medium $\left(\mathrm{Gibco}^{\circledR}\right.$, Life Technologies ${ }^{\mathrm{TM}}$, Invitrogen) supplemented with $10 \%$ Newborn calf serum (Gibco $\left.{ }^{\circledR}\right), 1 \%$ HEPES buffer $\left(\mathrm{Gibco}^{\circledR}\right.$ ) and 1\% $100 \mathrm{U} / \mathrm{mL}$ penicillin/streptomycin (PAA Laboratories $\mathrm{GmbH}$, Pasching, Austria).

\section{Endocrine treatment}

Cells received varying treatment regimens to evaluate the functional impact of oestrogen stimulation in contrast

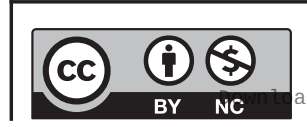

This work is licensed under a Creative Commons Attribution-NonCommercial 4.0 International License. ded from Bioscientifica.com at 04/26/2023 10:54:44AM 
to anti-oestrogen approaches. Chemicals used: oestrogen (=17 $\beta$-Estradiol; $\quad$ Sigma-Aldrich ${ }^{\circledR}$ Chemie $\left.\mathrm{GmbH}\right)$; endoxifen $\quad(=(\mathrm{E} / \mathrm{Z})-4-(1-(4-(2-(M e t h y l a m i n o) e t h o x y) \mathrm{p}$ henyl)-2-phenyl-1-buten-1-yl)-phenol hydrochloride hydrate (1:1 E/Z mixture), Sigma-Aldrich $\left.{ }^{\circledR}\right)$; fulvestrant $(=\quad$ (7a,17b)-7-(9-((4,4,5,5,5pentafluoropentyl)sulfinyl) nonyl)estra-1,3,5(10)-triene-3,17-diol, $\quad$ Sigma-Aldrich $\left.{ }^{\circledR}\right)$; dimethyl sulfoxide (DMSO; Sigma-Aldrich ${ }^{\circledR}$ ). DMSO served as solvent for oestrogen, endoxifen and fulvestrant. Cells were plated in 6-well culture plates in parallel and grown to 70-80\% confluence before treatment start. BT-20, MCF-7 and T-47D cells incubated under standard conditions in parallel served as controls. The hormone receptor-positive cell lines were pre-treated with oestrogen (5 $\mu \mathrm{M}, 24 \mathrm{~h})$. Following oestrogen stimulation, the cells received antioestrogen treatment with either endoxifen (15 nM) or fulvestrant (15 nM) for $24 \mathrm{~h}$. In vitro experiments were performed in triplicate.

\section{RNA isolation, reverse transcription (RT) and RT-qPCR}

Total RNA from in vitro experiments was isolated using TRIzol $^{\circledR}$ reagent (Life Technologies, Invitrogen ${ }^{\mathrm{TM}}$ ) following the manufacturer's protocol. In total, $1 \mu \mathrm{g}$ of purified RNA, as determined by optical densitometry, was transcribed to cDNA using Moloney murine leukemia virus reverse transciptase (Promega), RiboLock ${ }^{\mathrm{TM}}$ RNAse inhibitor (Fermentas Life Sciences, St. Leon-Rot, Germany), and anchored oligo dT Primer (T(9)VN(2)) (Apara Bioscience, Denzlingen, Germany). Prior to qPCR, contamination with genomic DNA was prevented by digestion $\left(1 \mathrm{~h}, 37^{\circ} \mathrm{C}\right)$ with dpnI enzyme (Fermentas Life Sciences). The cDNA served as template for PCR (35 cycles) using Taq polymerase (Roboklon, Berlin, Germany) and primers specific for the genes of interest (Supplementary Table 2). Gene expression levels were normalized against the geometric mean of Alas1, RPS18, beta actin using the $\Delta \Delta \mathrm{C}_{\mathrm{T}}$ method (Supplementary Table 2).

\section{Immunocytochemistry}

T-47D, MCF-7 and BT-20 cells were fixed subsequent to experimental treatment using ROTI® Histofix formaldehyde fixation reagent (4\% formaldehyde in PBS, pH 7, Carl Roth, Karlsruhe, Germany). An indirect immunoperoxidase technique was applied to visualize the target protein expression. Antigen retrieval was performed in a $10 \mathrm{mmol} / \mathrm{L}$ sodium citrate buffer $(\mathrm{pH}$ 6.0) followed by inhibition of endogenous peroxidase by incubation for 30 min with $3 \% \mathrm{H}_{2} \mathrm{O}_{2}$. After two washes in trissaline buffer, slides were incubated with $1 \%$ goat serum for 30 min to block unspecific staining. Following overnight incubation with the target protein antibody (Supplementary Table 3) at RT and two washing steps with PBS, slides were exposed to ImmPRESS peroxidase polymer reagent (BIOZOL, Eching, Germany) for $60 \mathrm{~min}$ at RT. Staining was achieved by 3,3-diaminobenzidine (DAB; BIOZOL, Eching, Germany) and the cells were counterstained with hemalaun (Merck). The colour intensity was quantified and evaluated with the software Image-Pro ${ }^{\circledR} 10$ (MEDIA Cybernetics, Rockville, USA), according to the manufacturer's specifications. For better comparison, the percentage staining in comparison to the cell surface was calculated. A staining below $5 \%$ of the area was considered negative.

\section{Statistical analysis}

Observed miRNA expression levels were graphically visualized in box plot diagrams, showing median and quartiles in cell lines MCF-7, T-47D and BT-20 under control conditions, endoxifen or fulvestrant treatment. The influence of treatment on miRNA expression levels of the different $\mathrm{BC}$ cell lines was investigated using a linear model with factor treatment (endoxifen or fulvestrant compared to control conditions) and cell line, including an interaction term.

\section{Results}

In the present study, we analysed the potential regulatory effects of fulvestrant and endoxifen on the expression of oestrogen receptor $\alpha$ and its known coactivators DEADbox-Protein DDX5 and DDX17. In parallel, the expression levels of DDX1, DDX23 and DDX 42, cyclin D1 and Ki67 were investigated.

\section{Gene expression and Immunocytochemistry}

All eight examined target genes were reliably detectable in the three in vitro models under standard culture conditions. The characteristics of the investigated three cell lines BT-20, MCF-7 and T-47D are summarized in Supplementary Table 1. Regression analysis based on the target-control value of BT-20 (intercept). As one exception, the target-control value from MCF-7 was applied as intercept in the case of oestrogen receptor $\alpha$. Subsequently the results were target-sorted (Fig. 1, Table 1

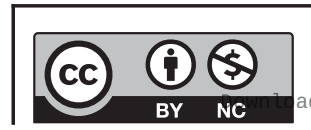

This work is licensed under a Creative Commons Attribution-NonCommercial 4.0 International License. ded from Bioscientifica.com at 04/26/2023 10:54:44AM 
Adcr

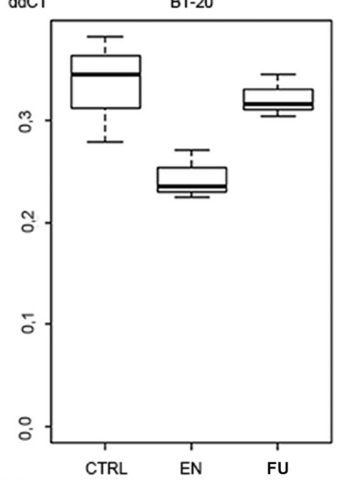

B

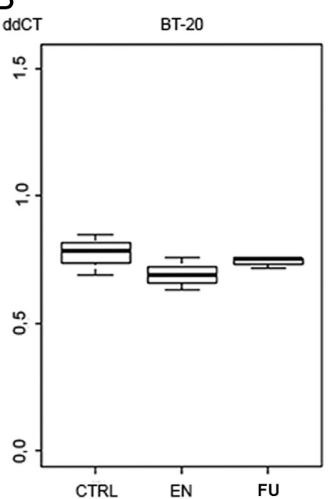

C

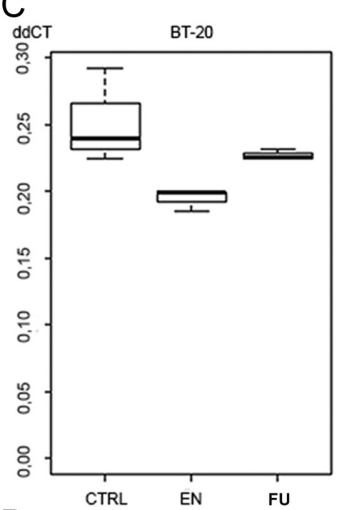

ddCT MCF-7

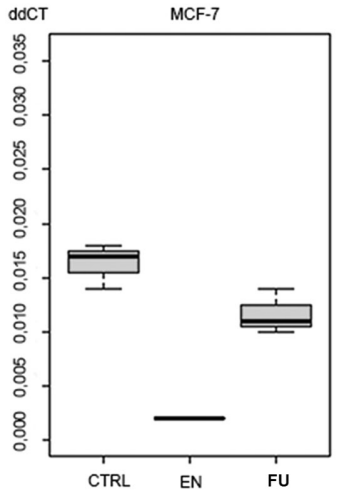

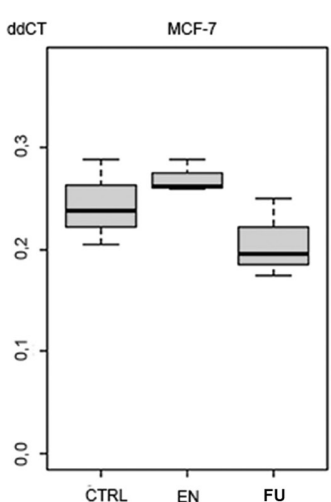
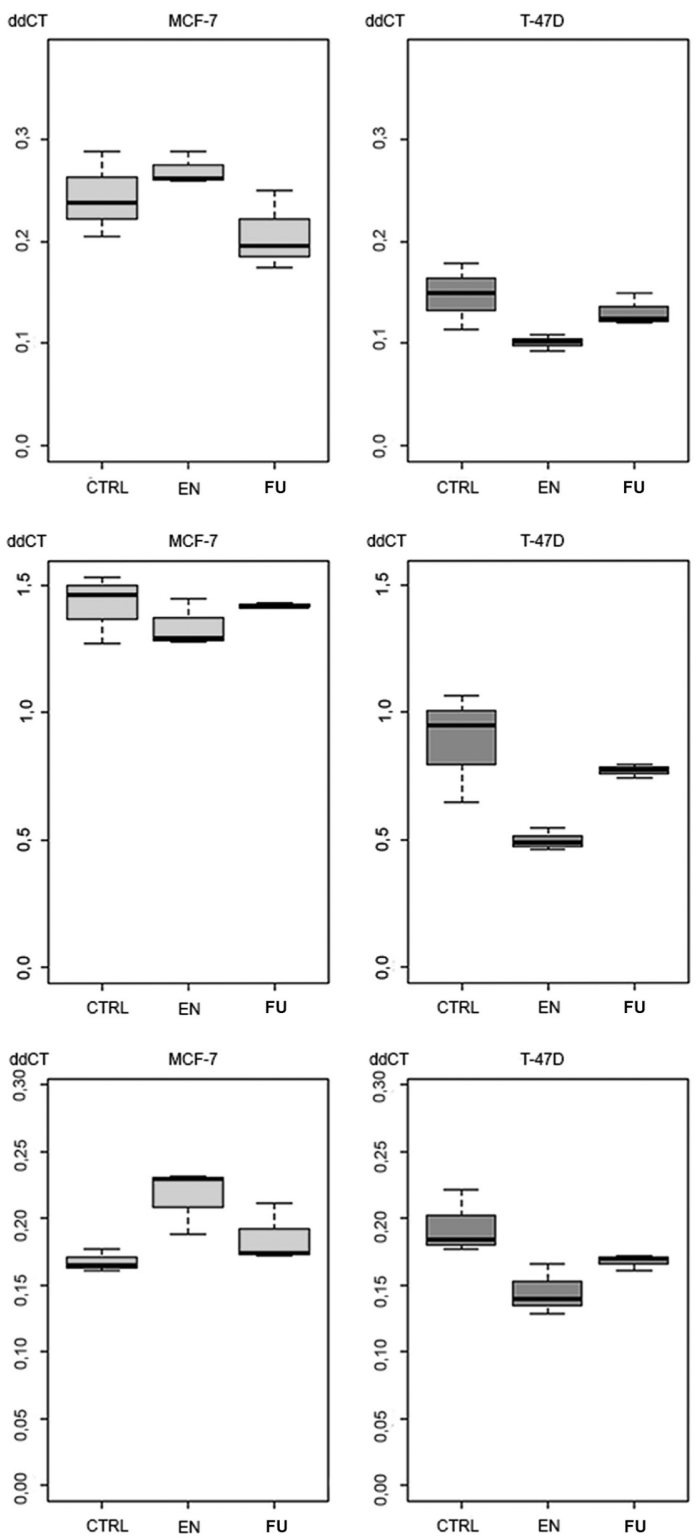

Figure 1

Box plot diagram of mRNA expression levels of DDX1 (A), DDX5 (B), DDX17 (C) and ER $(\mathrm{D})$ in response to endoxifen and fulvestrant. mRNA expression levels of DDX1, DDX5, DDX17 and ESR- $\alpha$ in breast cancer cell lines are displayed under anti-oestrogen treatment. Levels of secreted mRNA expression were determined in BT-20, MCF-7 and T-47D under control conditions (CTRL), endoxifen treatment (EN) and fulvestrant treatment (Fu). Box plots demonstrate median (thick black line), lower and upper quantile range (box lines), and standard deviation range (dashed lines bounded by horizontal lines). Based on triplicate experiments, real-time quantitative PCR. https://ec.bioscientifica.com https://doi.org/10.1530/EC-20-0281 (c) 2020 The authors Published by Bioscientifica Ltd

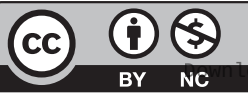

This work is licensed under a Creative Common Attribution-NonCommercial 4.0 International License.

ded from Bioscientifica,com at 04/26/2023 10:54:44AM via free access 
Table 1 Two-way analysis of variance for levels of deadbox-proteins 1, 5, 17 and ER $\alpha$ under control, with endoxifen and fulvestrant in three different breast cancer cell lines.

\begin{tabular}{|c|c|c|c|c|c|}
\hline Cell line & Treat & Estimate & Std. Error & $95 \% \mathrm{Cl}$ & $P$-value \\
\hline \multicolumn{6}{|l|}{ DDX1 } \\
\hline \multirow[t]{3}{*}{ ВT20 } & Intercept & 0.334 & 0.018 & 0.299 to 0.369 & 0.00 \\
\hline & En & -0.091 & 0.025 & -0.140 to 0.041 & 0.002 \\
\hline & $\mathrm{Fu}$ & -0.013 & 0.025 & -0.063 to 0.036 & 0.603 \\
\hline \multirow[t]{3}{*}{$\mathrm{T}-47 \mathrm{D}$} & Control & -0.187 & 0.025 & -0.236 to 0.138 & 0.00 \\
\hline & En & -0.46 & 0.025 & -0.096 to 0.003 & 0.082 \\
\hline & $\mathrm{Fu}$ & -0.016 & 0.025 & -0.066 to 0.033 & 0.525 \\
\hline \multirow[t]{3}{*}{ MCF-7 } & Control & -0.091 & 0.025 & -0.140 to 0.041 & 0.002 \\
\hline & En & 0.025 & 0.025 & -0.024 to 0.075 & 0.328 \\
\hline & $\mathrm{Fu}$ & -0.038 & 0.025 & -0.087 to 0.012 & 0.152 \\
\hline \multicolumn{6}{|l|}{ DDX5 } \\
\hline \multirow[t]{3}{*}{ BT20 } & Intercept & 0.773 & 0.057 & 0.662 to 0.884 & 0.00 \\
\hline & En & -0.081 & 0.080 & -0.238 to 0.076 & 0.326 \\
\hline & $\mathrm{Fu}$ & -0.033 & 0.080 & -0.190 to 0.124 & 0.686 \\
\hline \multirow[t]{3}{*}{$\mathrm{T}-47 \mathrm{D}$} & Control & 0.113 & 0.080 & -0.044 to 0.270 & 0.176 \\
\hline & En & -0.388 & 0.080 & -0.545 to -0.231 & 0.00 \\
\hline & $\mathrm{Fu}$ & -0.115 & 0.080 & -0.273 to 0.042 & 0.168 \\
\hline \multirow[t]{3}{*}{ MCF-7 } & Control & 0.648 & 0.080 & 0.490 to 0.805 & 0.00 \\
\hline & En & -0.084 & 0.080 & -0.241 to 0.074 & 0.311 \\
\hline & $\mathrm{Fu}$ & -0.003 & 0.080 & -0.161 to 0.154 & 0.967 \\
\hline \multicolumn{6}{|l|}{ DDX17 } \\
\hline \multirow[t]{3}{*}{ ВT20 } & Intercept & 0.252 & 0.011 & 0.230 to 0.274 & 0.000 \\
\hline & En & -0.057 & 0.016 & -0.089 to -0.026 & 0.002 \\
\hline & $\mathrm{Fu}$ & -0.025 & 0.016 & -0.056 to 0.006 & 0.136 \\
\hline \multirow[t]{3}{*}{ T-47D } & Control & -0.058 & 0.016 & -0.089 to -0.027 & 0.002 \\
\hline & En & -0.049 & 0.016 & -0.049 to -0.018 & 0.007 \\
\hline & $\mathrm{Fu}$ & -0.026 & 0.016 & -0.058 to 0.005 & 0.118 \\
\hline \multirow[t]{3}{*}{ MCF-7 } & Control & -0.084 & 0.016 & -0.116 to -0.053 & 0.000 \\
\hline & En & 0.049 & 0.016 & 0.017 to 0.080 & 0.007 \\
\hline & $\mathrm{Fu}$ & 0.018 & 0.016 & -0.013 to 0.049 & 0.276 \\
\hline \multicolumn{6}{|l|}{$\mathrm{ER} \alpha$} \\
\hline \multirow[t]{3}{*}{ MCF-7 } & Intercept & 0.016 & 0.002 & 0.013 to 0.020 & 0.000 \\
\hline & En & -0.014 & 0.003 & -0.019 to -0.009 & 0.000 \\
\hline & $\mathrm{Fu}$ & -0.005 & 0.003 & -0.010 to 0.000 & 0.087 \\
\hline \multirow[t]{3}{*}{ T-47D } & Control & 0.012 & 0.003 & 0.007 to 0.017 & 0.000 \\
\hline & En & -0.016 & 0.003 & -0.021 to -0.011 & 0.000 \\
\hline & $\mathrm{Fu}$ & -0.013 & 0.003 & -0.018 to -0.008 & 0.000 \\
\hline
\end{tabular}

and Supplementary Table 4). The protein expression was determined by immunocytochemical analysis in cell lines treated with endoxifen or fulvestrant compared to cells cultured under control conditions (Figs 2, 3, 4 and 5). A short summary of all results is shown in Fig. 6.

\section{ERa}

Endoxifen exposure created a significant decrease in ER $\alpha$ RNA expression in both hormone-receptor positive cell lines $(P<0.001)$. The treatment with fulvestrant also minimized the ER $\alpha$ expression. However, the decrease was highly significant only in T-47D cells. The RNA expression levels are reflected in corresponding protein expression. However, a stronger protein inhibition was observed in response to fulvestrant treatment.
The hormone receptor-negative cell line BT-20 did not exhibit any detectable ER $\alpha$ protein expression (Fig. 5).

\section{DDX1}

DDX1 expression was identified with significantly higher levels in the hormone receptor-negative cell line BT-20 compared to the hormone receptor-positive cell lines. Endoxifen treatment triggered a decrease of DDX1 RNA expression in BT-20 $(P=0.002)$. Similarly, in T-47D, the DDX1-diminishing drug-dependent effect did not reach significance but demonstrated a pronounced trend. In contrast, MCF-7 cells exhibited an endoxifen-driven not significant increase in DDX1 RNA levels. Fulvestrant treatment caused a uniform trend towards decreased DDX1 RNA expression among all cell lines tested. https://ec.bioscientifica.com https://doi.org/10.1530/EC-20-0281 (c) 2020 The authors Published by Bioscientifica Ltd 

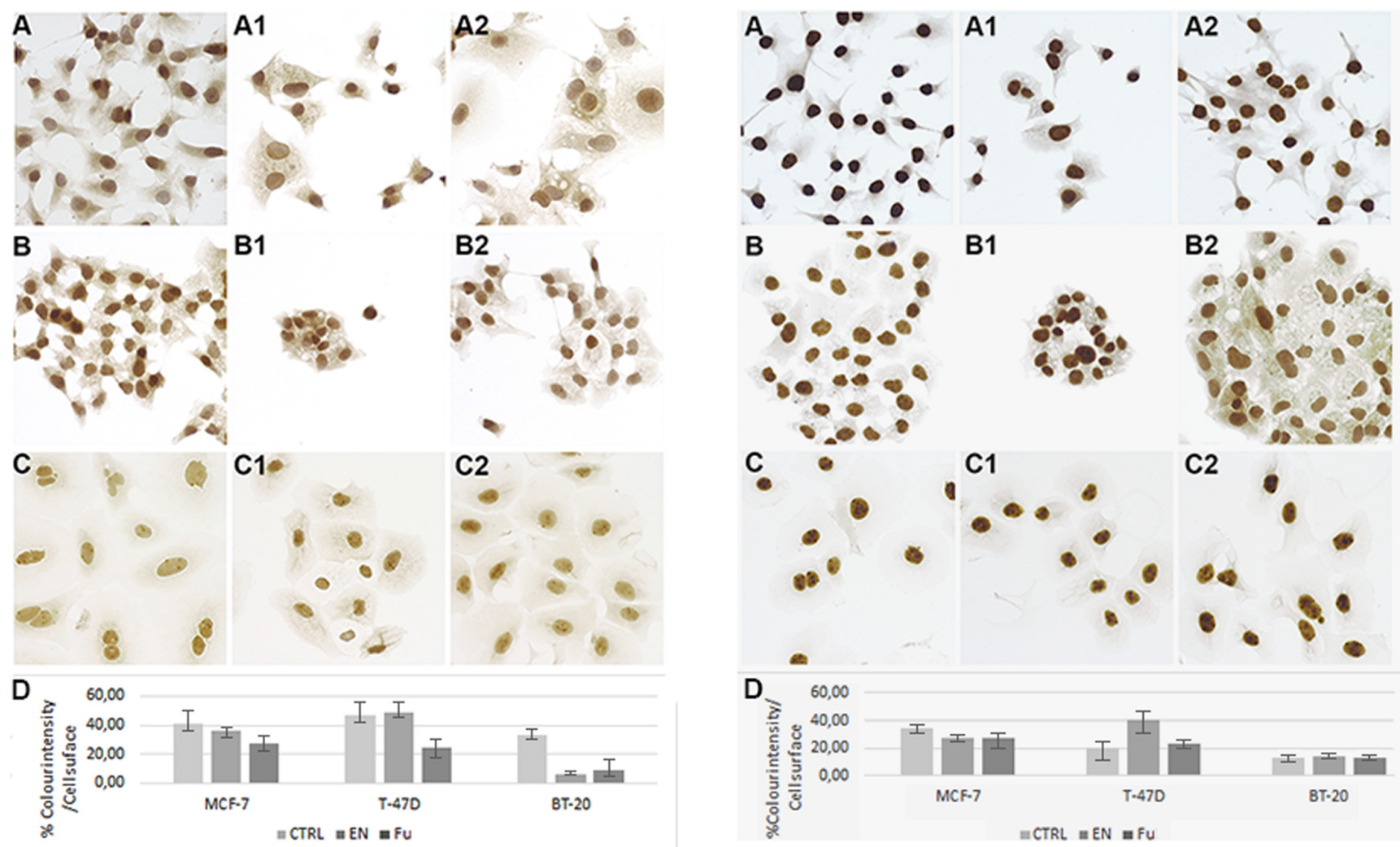

\section{Figure 2}

Immunocytochemical detection of DDX1 protein expression in breast cancer cell lines. (A) MCF-7, (B) T-47D, (C) BT-20 under control conditions, (1) after endoxifen and (2) fulvestrant treatment. Endoxifen decreases DDX1 in MCF-7 an increase in T-47D. Fulvestrant reduces the expression in both hormone-receptor positive cell line. In BT-20 cells the DDX1 protein expression decreases after endocrine treatment. Immunocytochemistry, triplicate experiments, counterstained with hemalaun. Magnification 400×. (D) Demonstration of the percentage immunocytochemical staining of the cell surface under control conditions, after endoxifen and fulvestrant treatment.

However, this effect did not reach significant differences. Immunocytochemical analysis underlines the triggering effect of endocrine treatment towards a DDX1 protein expression decrease in BT-20 cells. Fulvestrant caused a uniform decrease of DDX1 protein expression in both hormone-receptor positive cell lines tested. Endoxifen led to a slight reduction of DDX 1 protein expression in MCF-7 cells and increased the protein expression level in T-47D cells (Fig. 2).

\section{DDX5}

DDX5 RNA expression levels under standard culture conditions were higher in the ER-positive cell lines MCF-7 and T-47D compared to BT-20 cells, with pronounced

https://ec.bioscientifica.com https://doi.org/10.1530/EC-20-0281 (c) 2020 The authors Published by Bioscientifica Ltd

\section{Figure 3}

Immunocytochemical detection of DDX5 protein expression in breast cancer cell lines. (A) MCF-7, (B) T-47D, (C) BT-20 under control conditions, (1) after endoxifen and (2) fulvestrant treatment. In MCF-7 cell line endoxifen and fulvestrant decrease DDX5 protein expression. The protein expression in T47D showed the same tendency after fulvestrant. Endoxifen increases the protein. In BT-20 cell line the protein expression was unchanged after anti-hormonal treatment. Immunocytochemistry, triplicate experiments, counterstained with hemalaun. Magnification 400×. (D) Demonstration of the percentage immunocytochemical staining of the cell surface under control conditions, after endoxifen and fulvestrant treatment.

significance in MCF-7 cells $(P<0.001)$. In vitro models uniformly responded to endoxifen treatment with a DDX5 downregulation, reaching a significant level in T-47D cells $(P<0.001)$. Fulvestrant triggered a general decrease in DDX5 RNA expression of all cell types, nevertheless missing significance. The immunocytochemistry revealed a DDX5 protein level decrease in hormone-receptor positive cells after application of fulvestrant. In T-47D cells, the nuclear protein expression appeared stable in response to endoxifen, but an increase in DDX5 protein levels was detected in the cytoplasm. In MCF-7 cells, endoxifen caused a DDX5 expression decrease that was comparable to the extent triggered by fulvestrant. The DDX5 expression level in BT-20 remained on a stable level independent of endocrine interventions. 


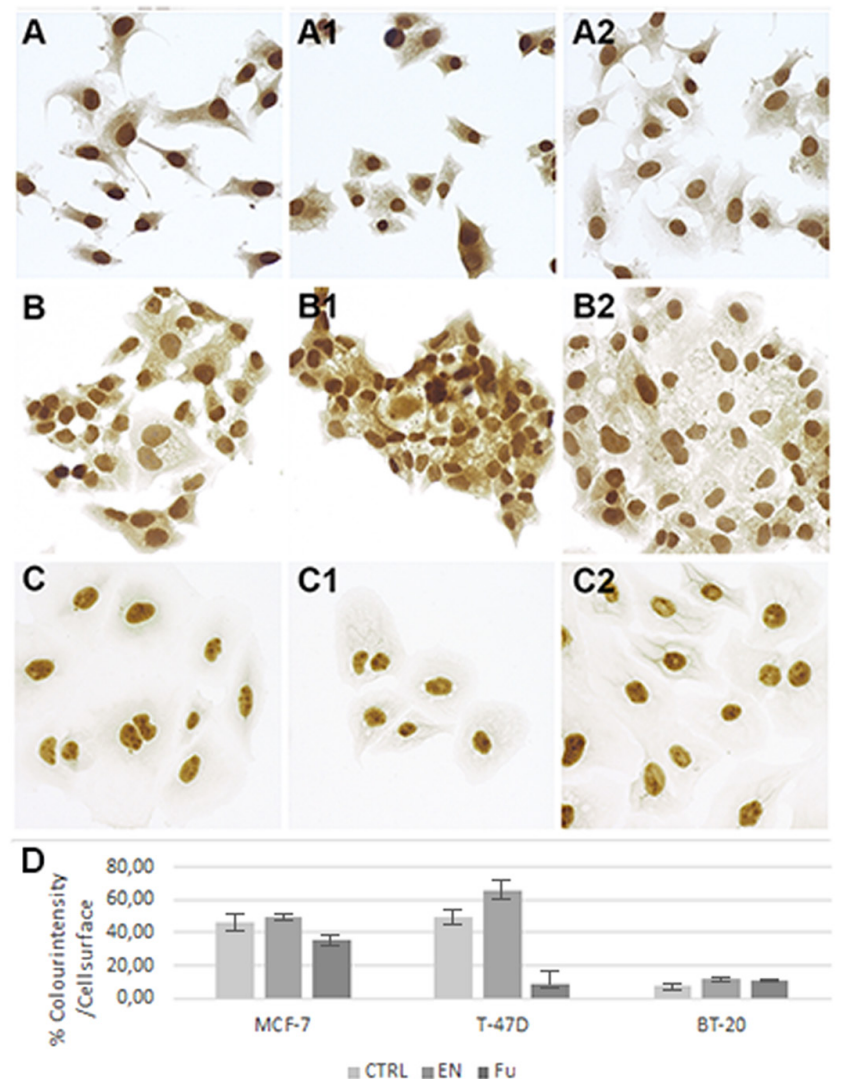

Figure 4

Immunocytochemical detection of DDX17 protein expression in breast cancer cell lines. (A) MCF-7, (B) T-47D, (C) BT-20 under control conditions, (1) after endoxifen and (2) fulvestrant treatment. Endoxifen leads to an increase of DDX protein expression in MCF-7 and T-47D cell line. In contrast fulvestrant decreases the protein expression. In BT-20 cell line the anti-hormonal treatment has no effect on the protein expression Immunocytochemistry, triplicate experiments, counterstained with hemalaun. Magnification 400×. (D) Demonstration of the percentage immunocytochemical staining of the cell surface under control conditions, after endoxifen and fulvestrant treatment.

\section{DDX17}

In comparison to BT-20 cells, the expression levels of DDX17 were significantly lower in MCF-7 $(P<0.001)$ and T-47D $(P=0.002)$ under control conditions. Endoxifen and fulvestrant exerted comparable effects on DDX17 RNA expression, creating a decrease in BT-20 and T-47D, while MCF-7 cells exhibited a drug-driven increase. However, only endoxifen treatment caused a significant difference in all cell lines tested. Immunocytochemically, fulvestrant triggered a decrease of DDX17 in MCF-7 and T-47D cells. However, endoxifen caused an increase in the dyeing intensity in both hormone-receptor positive cell lines. The DDX17 protein expression levels in BT-20 remained stable in control conditions vs endocrine treatment (Fig. 4).

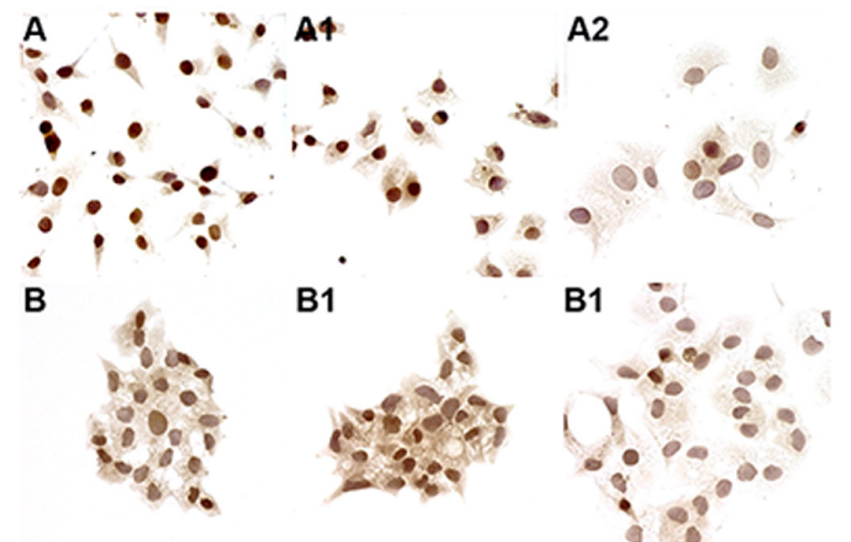

C

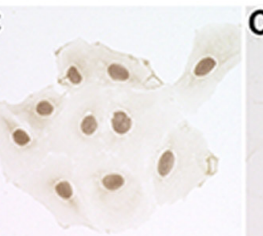

C1.
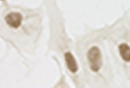

C2
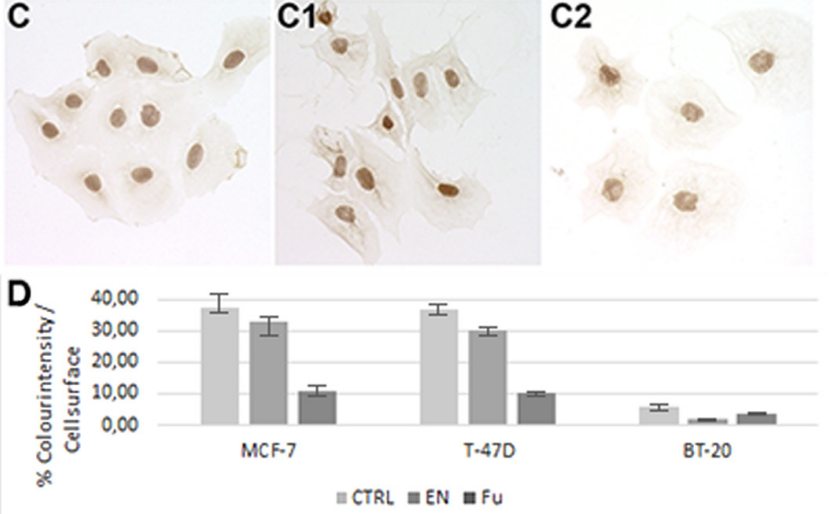

Figure 5

Immunocytochemical detection of ER $\alpha$ protein expression in breast cancer cell lines. (A) MCF-7, (B) T-47D, (C) BT-20 under (1) control conditions, (1) after endoxifen and (2) fulvestrant treatment. ER $\alpha$ protein expression under control conditions in MCF-7 and T47D is strong and concentrates on perinuclear compartments. The hormone receptornegative cell line BT-20 did not express a detectable ER $\alpha$. Endoxifen reduces the nuclear expression. Fulvestrant decreases the ER $\alpha$ protein expression. Immunocytochemistry, triplicate experiments, counterstained with hemalaun. Magnification 400×. (D) Demonstration of the percentage immunocytochemical staining of the cell surface under control conditions, after endoxifen and fulvestrant treatment.

\section{DDX23}

DDX23 RNA expression levels under standard culture conditions were higher in the hormone receptor-negative BT-20 cells compared to the hormone receptor-positive cell lines MCF-7 and T-47D. Significant DDX23 expression reduction was observed in all cell lines under the influence of endoxifen. Treatment with fulvestrant triggered a slight decline of the expression levels in each cell line, but with significantly changed levels in T-47D cells only. Since no commercial DDX23 antibody was available, protein detection of this target gene was elided.

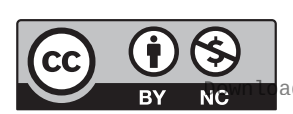

This work is licensed under a Creative Commons Attribution-NonCommercial 4.0 International License. ded from Bioscientifica.com at 04/26/2023 10:54:44AM 


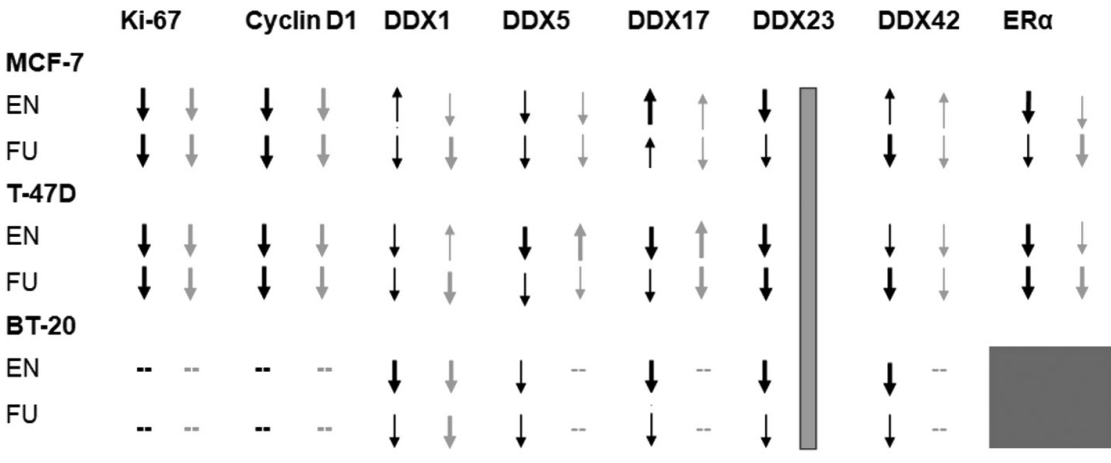

\section{Figure 6}

Summary and comparison of the results of RNA expressions analysis and immunocytochemistry. The thick arrows symbolize significant results $(P<0.01)$. The thin arrows show a trend but the results have not reached the significance level.

\section{DDX42}

In the hormone receptor-positive cell lines, the RNA expression of DDX42 was higher compared to the expression levels in BT-20 $(P<0.001)$ under standard conditions. The influence of endoxifen led to a significant decrease of the DDX42 RNA expression levels in BT-20 and to slight decrease in T-47D. In contrast, the RNA expression levels of DDX42 in MCF-7 cells increased, but not significantly. Fulvestrant-dependent reduction of DDX42 expression with significant extent was observed only in the hormone receptor-positive cell lines. The fulvestrant-driven significant decline of DDX42 RNA expression in hormone-receptor positive cells stands in contrast to the rather weak alterations observed on the protein level. DDX42 protein levels increased due to endoxifen exposition in MCF-7 cells. Again, the hormone receptor-negative cell line BT-20 did not exhibit any pronounced alterations on protein levels under endocrine treatment, which became apparent in the DDX42 immunocytochemical analysis (data not shown).

\section{Ki67}

Expression levels of the proliferation marker Ki67 were higher in BT-20 cells compared to the hormone receptorpositive cell lines MCF-7 and T-47D $(P<0.001)$. Both endocrine treatment options were incapable of altering Ki67 RNA and protein expression levels in BT-20. In the hormone receptor-positive cell lines MCF-7 and T-47D, therapy with endoxifen and fulvestrant led, as expected, to a significant reduction of Ki67 RNA expression. The corresponding protein expression in response to antiestrogen treatment was reduced, too.

\section{Cyclin D1}

Cyclin D1 RNA expression was higher in the hormone receptor-positive cell lines MCF-7 $(P<0.001)$ and T-47D
$(P=0.09)$ compared to the hormone receptor-negative cell line BT-20. Due to endoxifen treatment, the expression rate of cyclin D1 was reduced in each cell line. In the case of MCF-7 and T-47D, the observed decrease was highly significant $(P<0.001)$. Following the application of fulvestrant, the expression level of cyclin D1 declined in MCF-7 $(P<0.001)$ and T-47D $(P=0.01)$. The corresponding protein expression levels were reduced, too.

\section{Discussion}

In this study, we investigated the potential effects triggered by endocrinologically active anti-breast cancer drugs on ER $\alpha$ and its coactivators DDX5 and DDX17, as well as the DEADbox proteins 1, 23, 42 and the proliferation markers cyclin D1 and Ki-67.

$\mathrm{ER} \alpha$ plays a crucial role in signalling pathways regulating proliferation processes in hormone-receptor positive breast cancer cells (5). In response to exposition to the ER $\alpha$-targeting drugs endoxifen and fulvestrant, the mRNA and protein expression levels of ER $\alpha$ decreased. As expected, ER $\alpha$ inhibition was found associated with a decline in Ki67 mRNA expression under the influence of fulvestrant and endoxifen. Immunocytochemically, drug-dependent Ki67 downregulation could be confirmed on the protein level. In parallel, a similar effect could be observed regarding cyclin D1 mRNA expression, which also characterizes as a proliferation marker.

DDX1 expression has been associated with different types of tumours including neuroblastoma (27), Wilms tumour (28), retinoblastoma (29) and testicular carcinoma (30). Germain et al. described the correlation between overexpression and elevated cytoplasmic DDX1 protein levels with early recurrence in BC. DDX1 overexpression was found in hormone-receptor negative BC (23). However, Taunk et al. hypothesized an association

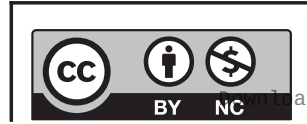

This work is licensed under a Creative Commons Attribution-NonCommercial 4.0 International License. ded from Bioscientifica.com at 04/26/2023 10:54:44AM via free access 
between the expression of DDX1 with improved local relapse-free-, distant metastasis-free- and overall survival in patients diagnosed with early-stage node-negative BC (24). Additionally, the data reported also indicate a negative association of DDX1 with the aggressive triplenegative molecular subtype of BC (24). Interestingly, our analysis showed significantly higher RNA expression levels of DDX1 in hormone receptor-negative cell line BT-20 compared to the hormone-receptor positive cell lines. The current data rather emphasize the results of Germain et al. Exposition to endoxifen triggered a significant decrease of DDX1 RNA expression levels in BT-20 cells. Under the influence of fulvestrant, a reduction of DDX1 expression was also observed. However, this reduction was not statistically significant. The mechanism of DDX1 expression downregulation in hormone receptor-negative cell lines in response to the endocrine drugs remains undefined. There might be another pathway which is more strongly influenced by endoxifen than by fulvestrant leading to the reduction of DDX1 expression. The proliferation marker Ki-67 was higher in BT-20 cells under standard culture conditions, too. However, compared to DDX1, the expression level of Ki67 in BT-20 cells remains stable in response to antihormonal treatment. Altered DDX1 expression levels did not reveal a direct association with proliferation markers. At protein level, the decrease in expression of DDX1 was confirmed. In hormone-receptor positive cell line T-47D, both drugs led to a reduction of DDX1 RNA expression. Immunocytochemically, DDX1 protein expression levels in T47-D remained almost stable comparing endoxifen exposure vs standard conditions. In contrast, in MCF-7 cells endoxifen triggered an increase in DDX1 RNA levels, combined with a decrease in corresponding protein levels. Worth mentioning, T-47D cells can be characterized by reduced proliferation rate compared to the MCF-7 cells in general. One possible explanation might be that T-47D cells still experienced a decrease of DDX1, while a reactive overexpression already progressed in MCF-7 cells. The results suggest, as hypothesized by Balko et al., the existence of treatment-related interactions with DDX1 expression in breast tumours (31).

The functional impact of DDX5 in tumourigenesis could be elucidated by various studies. Altered regulatory pathways contribute to tumourigenesis, invasion, proliferation and metastasis. With respect to BC, DDX5 is a known modifier involved in several pathways, for example, Wnt/B catenin signalling (32), oestrogen signalling (33) and mTOR signalling (34). Via interaction of DDX5 with B catenin, alteration in expression of downstream genes cMyc, cjun and cyclin D1 were described, which directly promote an increase in cell proliferation (35). Ongoing research targets to the identification of DDX5 inhibitory agents to define a potential novel anti-cancer therapeutic drug. Kost et al. identified DDX5 as cellular target of RX-5902, a small molecule exhibiting strong growth inhibitory impact in several human cancer cell lines (36). In breast tumours, increased DDX5 expression correlates with the expression of Ki67, which indicates the tumourbiological background for poor prognosis and high invasiveness (37). In response to anti-estrogen therapy, DDX5 RNA expression levels decreased in both hormone-receptor positive cell lines. At the same time a significant drop of Ki67 and cyclin D1 mRNA levels was observed. Immunocytochemically, the protein levels of DDX5 appeared to increase following anti-oestrogen drug treatment in T-47D cells. This could possibly be interpreted as an attempt by the cell to counteract the anti-proliferative effect of these drugs. Additionally, this could also be a putative explanation for the shift of DDX5 protein from nuclear compartments to the cytoplasm of T-47D cells. The corresponding result would be possible via the Wnt/B catenin signalling with an increase in cyclin D1 over the course of time. Moreover, the increase of DDX5 protein could activate mTOR via phosphorylation which enables the synthesis of proteins responsible for proliferation (e.g. cyclin D1) (34). With respect to endocrine resistance, cyclin D1 mediated pathways are dysregulated (38). Lange et al. could identify an essential activation of these pathways after prolonged ER blockade (38).

Similar to DDX5, DDX17 can also influence tumourigenesis and proliferation. DX17 has also been identified as a coactivator for the ER signalling pathway $(16,21)$. DDX17 expression is correlated with increased relapse-free and overall survival, and is inversely associated with Her2/neu expression (20). A knockdown of DDX17 in MCF-7 cells reduces the ER $\alpha$-dependent growth (16). In this study, both endoxifen and fulvestrant triggered a decrease of DDX17 RNA expression in T-47D cells. However, only endoxifen treatment caused a statistically significant difference $(P=0.007)$ with increased mRNA expression levels in MCF-7 cells. Shin et al. showed an association between DDX17 and expression of several $\beta$-catenin downstream targets including c-myc, cyclin D1, fra-1 and c-jun. A knockdown of DDX17 decreased the expression of these downstream targets correlating with a subsequent reduction of cell proliferation (39). The overexpression of DDX17 in MCF-7 cells could be a regulatory mechanism to ensure proliferation via the $\beta$-catenin pathway in the sense of endocrine resistance.

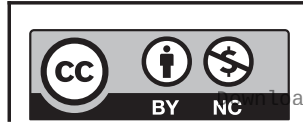

This work is licensed under a Creative Commons Attribution-NonCommercial 4.0 International License. ded from Bioscientifica.com at 04/26/2023 10:54:44AM 
The reason for an endoxifen-driven significant drop of DDX17 in the hormone-receptor negative cell line BT-20 remains unclear. Potentially, endoxifen could also influence alternative oestrogen receptor-independent pathways that decrease the DDX17 mRNA level. However, this phenomenon could not be confirmed on the protein level.

DDX42 binds and counteracts ASPP2, a major apoptosis inducer known to enhance p53 transactivation of pro-apoptotic genes (26). Fulvestrant treatment in vitro led to decreased DDX42 expression on both the mRNA and protein level. While DDX 42 decreased under the influence of endoxifen in T-47D cells, RNA overexpression was observed in MCF-7 cells. Corresponding protein levels were observed immunocytologically. DDX42 is more closely related to DDX5 and DDX17 than any other DEADbox protein (40). Analogous to DDX5 and DDX17, the different reaction of the two hormone-receptor positive cell lines might be explained by the different growth rates. An increase of DDX42 has an anti-apoptotic effect by counteracting ASPP2. This might be a beginning of endocrine resistance. Interestingly, the mRNA overexpression of DDX42 in MCF-7 cells was only found in the endoxifen setting.

Treatment-dependent alterations in the mRNA expression of DDX42, DDX17, DDX5 and DDX1 caused by endoxifen and/or fulvestrant were detected in the hormonereceptor negative cell line BT-20. These alterations raise new questions in respect of the so far underestimated reactivity of ER-negative cells in response to anti-oestrogenic interventions. In hormone-receptor positive BC, DDX5 and DDX 17 have been identified as a coactivators for the ER signalling pathway $(16,21)$. A coactivation of p53 was also described (22). This might be the important checkpoint. Possibly, the DEADbox proteins exert functions in tumourigenesis in hormone-receptor negative BC as well. However, no significant modification became apparent on the protein level. The absent modification might contradict the hypothesis. Nevertheless, a possible explanation for the absent modification of the protein level could be the slow-proliferating BT-20 cells. This could result in a delayed reaction on the protein level. Furthermore, an autoregulatory mechanism of mRNA and protein is plausibly one reason for the difference between mRNA and protein expression. A range of generegulatory active genes dispose of an autoregulatory loop, for example, hTra2-beta (41).

The present study is limited by its in vitro character. Nevertheless, novel insights in the regulatory impact of endocrine drugs on the expression of $\mathrm{BC}$-associated genes could be demonstrated. We examined whether there are any connections between the DEADbox proteins and anti-hormonal treatment. A possible reference to various pathways from the literature was established. However, further studies are necessary to gain more insight in the signalling pathways involved.

\section{Conclusion}

This in vitro study detects drug-driven expression alterations of the oestrogen coactivators DDX5 and DDX17. A variation of other investigated DEADbox proteins (DDX1, DDX23 and DDX42) was also observed. Whether these changes play a role in the anti-cancer drug resistance mechanism has to be clarified in further studies. DDX5 appears to be a novel target for cancer treatment. RX-5902 exhibits strong growth inhibition in several human cancer cell lines by interaction and inhibition of DDX5. Further research should focus on the elucidation of regulatory pathways associated with DEADbox proteins and the development of target-oriented inhibitors.

\section{Supplementary materials}

This is linked to the online version of the paper at https://doi.org/10.1530/ EC-20-0281.

\section{Declaration of interest}

The authors declare that there is no conflict of interest that could be perceived as prejudicing the impartiality of the research reported.

\section{Funding}

This research did not receive any specific grant from any funding agency in the public, commercial or not-for-profit sector.

\section{Availability of data and materials}

The datasets analysed during the current study are available from the corresponding author on reasonable request.

\section{Author contribution statement}

$\mathrm{M} \mathrm{H}, \mathrm{J} A, \mathrm{~K} \mathrm{~B}, \mathrm{~A} \mathrm{R}, \mathrm{M} J$ and T E designed the study concept. A R, M J and C N performed experiments (cell culture, RNA isolation, RT-qPCR, immunocytochemistry). G R performed statistical analysis. $M H, J A, K B$,

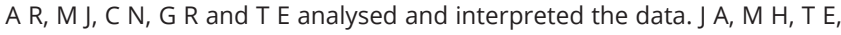
$K B$ and $G R$ wrote the manuscript in consultation with and under critical revision of $M$ J, C N, A R and I J B. J A, T E and $M H$ supervised the overall experimental design. All authors critically reviewed the manuscript and approved the final version.
This work is licensed under a Creative Commons Attribution-NonCommercial 4.0 International License. ded from Bioscientifica.com at 04/26/2023 10:54:44AM via free access 


\section{References}

1 Ferlay J, Colombet M, Soerjomataram I, Dyba T, Randi G, Bettio M, Gavin A, Visser O \& Bray F. Cancer incidence and mortality patterns in Europe: estimates for 40 countries and 25 major cancers in 2018. European Journal of Cancer 2018103 356-387. (https://doi. org/10.1016/j.ejca.2018.07.005)

2 Deroo BJ \& Korach KS. Estrogen receptors and human disease. Journal of Clinical Investigation 2006116 561-570. (https://doi.org/10.1172/ JCI27987)

3 Acevedo ML \& Kraus WL. Transcriptional activation by nuclear receptors. Essays in Biochemistry 200440 73-88. (https://doi. org/10.1042/bse0400073)

4 McEwan IJ. Sex, drugs and gene expression: signalling by members of the nuclear receptor superfamily. Essays in Biochemistry 200440 1-10. (https://doi.org/10.1042/bse0400001)

5 Orlando L, Schiavone P, Fedele P, Calvani N, Nacci A, Rizzo P, Marino A, D'Amico M, Sponziello F, Mazzoni E, et al. Molecularly targeted endocrine therapies for breast cancer. Cancer Treatment Reviews 201036 (Supplement 3) S67-S71. (https://doi.org/10.1016/ S0305-7372(10)70023-2)

6 Kuiper GG, Enmark E, Pelto-Huikko M, Nilsson S \& Gustafsson JA. Cloning of a novel receptor expressed in rat prostate and ovary. PNAS 199693 5925-5930. (https://doi.org/10.1073/pnas.93.12.5925)

7 Pietras RJ. Biologic basis of sequential and combination therapies for hormone-responsive breast cancer. Oncologist 200611 704-717. (https://doi.org/10.1634/theoncologist.11-7-704)

8 Hoskins JM, Carey LA \& McLeod HL. CYP2D6 and tamoxifen: DNA matters in breast cancer. Nature Reviews: Cancer 20099 576-586. (https://doi.org/10.1038/nrc2683)

9 Johnson MD, Zuo H, Lee KH, Trebley JP, Rae JM, Weatherman RV, Desta Z, Flockhart DA \& Skaar TC. Pharmacological characterization of 4-hydroxy-N-desmethyl tamoxifen, a novel active metabolite of tamoxifen. Breast Cancer Research and Treatment 200485 151-159. (https://doi.org/10.1023/B:BREA.0000025406.31193.e8)

10 Desta Z, Ward BA, Soukhova NV \& Flockhart DA. Comprehensive evaluation of tamoxifen sequential biotransformation by the human cytochrome P450 system in vitro: prominent roles for CYP3A and CYP2D6. Journal of Pharmacology and Experimental Therapeutics 2004 310 1062-1075. (https://doi.org/10.1124/jpet.104.065607)

11 Early Breast Cancer Trialists' Collaborative Group (EBCTCG), Davies C, Godwin J, Gray R, Clarke M, Cutter D, Darby S, McGale P, Pan HC, Taylor C, et al. Relevance of breast cancer hormone receptors and other factors to the efficacy of adjuvant tamoxifen: patient-level meta-analysis of randomised trials. Lancet 2011378 771-784. (https://doi.org/10.1016/S0140-6736(11)60993-8)

12 DeFriend DJ, Anderson E, Bell J, Wilks DP, West CM, Mansel RE $\&$ Howell A. Effects of 4-hydroxytamoxifen and a novel pure antioestrogen (ICI 182780) on the clonogenic growth of human breast cancer cells in vitro. British Journal of Cancer 199470 204-211. (https://doi.org/10.1038/bjc.1994.281)

13 Dauvois S, White R \& Parker MG. The antiestrogen ICI 182780 disrupts estrogen receptor nucleocytoplasmic shuttling. Journal of Cell Science 1993106 1377-1388.

14 DeFriend DJ, Howell A, Nicholson RI, Anderson E, Dowsett M, Mansel RE, Blamey RW, Bundred NJ, Robertson JF \& Saunders C. Investigation of a new pure antiestrogen (ICI 182780) in women with primary breast cancer. Cancer Research 1994 54 408-414.

15 LP DAP, Inventor. FASLODEX* (fulvestrant) prescribing information, 07/2018.

16 Janknecht R. Multi-talented DEAD-box proteins and potential tumor promoters: p68 RNA helicase (DDX5) and its paralog, p72 RNA helicase (DDX17). American Journal of Translational Research 20102 223-234.

17 Clark EL, Coulson A, Dalgliesh C, Rajan P, Nicol SM, Fleming S, Heer R, Gaughan L, Leung HY, Elliott DJ, et al. The RNA helicase p68 is a novel androgen receptor coactivator involved in splicing and is overexpressed in prostate cancer. Cancer Research 200868 7938-7946. (https://doi.org/10.1158/0008-5472.CAN-08-0932)

18 Bates GJ, Nicol SM, Wilson BJ, Jacobs AM, Bourdon JC, Wardrop J, Gregory DJ, Lane DP, Perkins ND \& Fuller-Pace FV. The DEAD box protein p68: a novel transcriptional coactivator of the p53 tumour suppressor. EMBO Journal 200524 543-553. (https://doi.org/10.1038/ sj.emboj.7600550)

19 Fuller-Pace FV \& Ali S. The DEAD box RNA helicases p68 (Ddx5) and p72 (Ddx17): novel transcriptional co-regulators. Biochemical Society Transactions 200836 609-612. (https://doi.org/10.1042/BST0360609)

20 Wortham NC, Ahamed E, Nicol SM, Thomas RS, Periyasamy M, Jiang J, Ochocka AM, Shousha S, Huson L, Bray SE, et al. The DEAD-box protein p72 regulates ERalpha-/oestrogen-dependent transcription and cell growth, and is associated with improved survival in ERalpha-positive breast cancer. Oncogene 200928 4053-4064. (https://doi.org/10.1038/onc.2009.261)

21 Dutertre M, Gratadou L, Dardenne E, Germann S, Samaan S, Lidereau R, Driouch K, de la Grange P \& Auboeuf D. Estrogen regulation and physiopathologic significance of alternative promoters in breast cancer. Cancer Research 201070 3760-3770. (https://doi.org/10.1158/0008-5472.CAN-09-3988)

22 Fuller-Pace FV. DEAD box RNA helicase functions in cancer. RNA Biology 201310 121-132. (https://doi.org/10.4161/rna.23312)

23 Germain DR, Graham K, Glubrecht DD, Hugh JC, Mackey JR \& Godbout R. DEAD box 1: a novel and independent prognostic marker for early recurrence in breast cancer. Breast Cancer Research and Treatment 2011127 53-63. (https://doi.org/10.1007/s10549-0100943-7)

24 Taunk NK, Goyal S, Wu H, Moran MS, Chen S \& Haffty BG. DEAD box 1 (DDX1) expression predicts for local control and overall survival in early stage, node-negative breast cancer. Cancer 2012118 888-898. (https://doi.org/10.1002/cncr.26352)

25 Mao G, Jin H \& Wu L. DDX23-Linc00630-HDAC1 axis activates the Notch pathway to promote metastasis. Oncotarget 20178 38937-38949. (https://doi.org/10.18632/oncotarget.17156)

26 Uhlmann-Schiffler H, Kiermayer S \& Stahl H. The DEAD box protein Ddx42p modulates the function of ASPP2, a stimulator of apoptosis. Oncogene 200928 2065-2073. (https://doi.org/10.1038/ onc.2009.75)

27 Squire JA, Thorner PS, Weitzman S, Maggi JD, Dirks P, Doyle J, Hale M \& Godbout R. Co-amplification of MYCN and a DEAD box gene (DDX1) in primary neuroblastoma. Oncogene 199510 1417-1422.

28 Noguera R, Villamon E, Berbegall A, Machado I, Giner F, Tadeo I, Navarro S \& Llombart-Bosch A. Gain of MYCN region in a Wilms tumor-derived xenotransplanted cell line. Diagnostic Molecular Pathology 201019 33-39. (https://doi.org/10.1097/ PDM.0b013e3181b11a9d)

29 Godbout R \& Squire J. Amplification of a DEAD box protein gene in retinoblastoma cell lines. PNAS 199390 7578-7582. (https://doi. org/10.1073/pnas.90.16.7578)

30 Tanaka K, Okamoto S, Ishikawa Y, Tamura H \& Hara T. DDX1 is required for testicular tumorigenesis, partially through the transcriptional activation of 12p stem cell genes. Oncogene 200928 2142-2151. (https://doi.org/10.1038/onc.2009.89)

31 Balko JM \& Arteaga CL. Dead-box or black-box: is DDX1 a potential biomarker in breast cancer? Breast Cancer Research and Treatment 2011 127 65-67. (https://doi.org/10.1007/s10549-010-1105-7)

32 Yang L, Lin C \& Liu ZR. Phosphorylations of DEAD box p68 RNA helicase are associated with cancer development and cell proliferation. Molecular Cancer Research 20053 355-363. (https://doi. org/10.1158/1541-7786.MCR-05-0022)

33 Guturi KK, Sarkar M, Bhowmik A, Das N \& Ghosh MK. DEADbox protein $\mathrm{p} 68$ is regulated by beta-catenin/transcription factor 4 to maintain a positive feedback loop in control of breast cancer

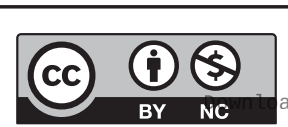

This work is licensed under a Creative Commons Attribution-NonCommercial 4.0 International License. ded from Bioscientifica, com at 04/26/2023 10:54:44AM 
breast cancer cells. Molecular and Cellular Proteomics 201211 M111.011932. (https://doi.org/10.1074/mcp.M111.011932) org/10.1186/s13058-014-0496-5)

34 Kokolo M \& Bach-Elias M. Downregulation of p68 RNA helicase (DDX5) activates a survival pathway involving mTOR and MDM2 signals. Folia Biologica 201763 52-59.

35 Wang Z, Luo Z, Zhou L, Li X, Jiang T \& Fu E. DDX5 promotes proliferation and tumorigenesis of non-small-cell lung cancer cells by activating beta-catenin signaling pathway. Cancer Science 2015106 1303-1312. (https://doi.org/10.1111/cas.12755)

36 Kost GC, Yang MY, Li L, Zhang Y, Liu CY, Kim DJ, Ahn CH, Lee YB \& Liu ZR. A novel anti-cancer agent, 1-(3,5-dimethoxyphenyl)-4 -((6-fluoro-2-methoxyquinoxalin-3-yl)aminocarbonyl]piperazin e (RX-5902), interferes with beta-catenin function through Y593 phospho-p68 RNA helicase. Journal of Cellular Biochemistry 2015116 1595-1601. (https://doi.org/10.1002/jcb.25113)

37 Wang D, Huang J \& Hu Z. RNA helicase DDX5 regulates microRNA expression and contributes to cytoskeletal reorganization in basal
38 Lange CA \& Yee D. Killing the second messenger: targeting loss of cell cycle control in endocrine-resistant breast cancer. EndocrineRelated Cancer 201118 C19-C24. (https://doi.org/10.1530/ERC-110112)

39 Shin S, Rossow KL, Grande JP \& Janknecht R. Involvement of RNA helicases p68 and p72 in colon cancer. Cancer Research 200767 7572-7578. (https://doi.org/10.1158/0008-5472.CAN-06-4652)

40 Uhlmann-Schiffler H, Rossler OG \& Stahl H. The mRNA of DEAD box protein $\mathrm{p} 72$ is alternatively translated into an $82-\mathrm{kDa}$ RNA helicase. Journal of Biological Chemistry 2002277 1066-1075. (https://doi. org/10.1074/jbc.M107535200)

41 Stoilov P, Daoud R, Nayler O \& Stamm S. Human tra2-beta1 autoregulates its protein concentration by influencing alternative splicing of its pre-mRNA. Human Molecular Genetics 200413 509-524. (https://doi.org/10.1093/hmg/ddh051)

Received in final form 7 October 2020

Accepted 12 October 2020

Accepted Manuscript published online 13 October 2020
This work is licensed under a Creative Commons Attribution-NonCommercial 4.0 International License. ded from Bioscientifica.com at 04/26/2023 10:54:44AM via free access 